\title{
Hydrogen Release from Simulated Sludge and Saltcake
}

by

R. A. Peterson

Westinghouse Savannah River Company

$Q$

Savannah River Site

Aiken, South Carolina 29808

This paper was prepared in connection with work done under the above contract number with the U.S. Department of Energy. By acceptance of this paper, the publisher and/or recipient acknowledges the U.S. Government's right to retain a nonexclusive, royalty-free license in and to any copyright covering this paper, along with the right to reproduce and to authorize others to reproduce all or part of the copyrighted paper. 


\section{DISCLAIMER}

This report was prepared as an account of work sponsored by an agency of the United States Government. Neither the United States Government nor any agency thereof, nor any of their employees, makes any warranty, express or implied, or assumes any legal liability or responsibility for the accuracy, completeness, or usefulness of any information, apparatus, product, or process disclosed, or represents that its use would not infringe privately owned rights. Reference herein to any specific commercial product, process, or service by trade name, trademark, manufacturer, or otherwise does not necessarily constitute or imply its endorsement, recommendation, or favoring by the United States Government or any agency thereof. The views and opinions of authors expressed herein do not necessarily state or reflect those of the United States Government or any agency thereof.

This report has been reproduced directly from the best available copy.

Available to DOE and DOE contractors from the Office of Scientific and Technical Information, P. O. Box 62, Oak Ridge, TN 37831; prices available from (423) 576-8401.

Available to the public from the National Technical Information Service, U. S. Department of Commerce, 5285. Port Royal Road, Springfield, VA 22161. 


\section{DISCLAIMER}

Portions of this document may be illegible in electronic image products. Images are produced from the best available original document. 
Distribution

703-H

C.L. Crawford

S.D. Fink

773-41A

H.E. Flanders

J.R. Hester

773-A

730-1B

$703-\mathrm{H}$

730-1B

W.N. Kennedy

B.L. Lewis

G.E. Mertz

703-H

W.L. Tamosaitis

730-1B

T. J. Lex,

A.H. Weber

J.S. Bollinger

Z.H. Qureshi

D.B. Burns

773-A

703-H

$773-\mathrm{A}$

786-6A

786-5A

786-5A

E.D. Lee

241-152H

M.S. Hay

$773-42 \mathrm{~A}$

T. M. Monahon

$703-\mathrm{H}$

F. Fondeur

$773-62 \mathrm{~A}$

N.E. Bibler

$773-\mathrm{A}$

D.T. Hobbs

D.D. Walker

R. H. Spires

V.G. Dickert

L.M. Papouchado

W.E. Stevens

M.J. Barnes

773-A

773-A

703-H

703-H

773-A

773-A

773-A

773-42A

703-H

M. D. Johnson

J. W. McCollough

J. P. Morin

G. T. Wright

703-H

703-H

773-A

W. B. VanPelt

T.C. Temple

676-1T

703-H 
Hydrogen Release from Simulated Sludge and Saltcake

R. A. Peterson

Publication Date: September 24, 1998

Westinghouse Savannah River Company Savannah River Technology Center Aiken, SC 29808

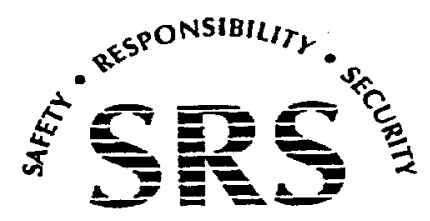




\section{Page 2 of 13}

September 24, 1998

\section{SUMMARY}

Investigations into the nature and extent of hydrogen release from high level waste sludge and saltcake provide the following insights.

- Saltcake retains the majority of trapped gases during agitation events (including earthquakes).

- Of the nine tanks of concern from release of hydrogen during seismic events, three likely contain little trapped gas due to high thermal gradients in these tanks.

- Instrumentation of Tanks $7 \mathrm{~F}$ and $13 \mathrm{H}$ to verify this conclusion is strongly recommended.

- The trapped gas in eight of the nine tanks of interest likely contain significantly less than $50 \%$ hydrogen.

- Additional testing is underway to confirm this conclusion.

- Sloshing of sludge and supernate in a vessel releases trapped gases.

-Material in the convective (sloshing) zone of the vessel releases nearly all trapped gas.

- Material in the impulsive zone (lower portion of the material that moves as a solid body) of the vessel releases little trapped gas.

- Sloshing will likely occur to some extent in all high level waste tanks that contain supernate and sludge during earthquakes. Current analyses suggest that the majority of this material will fluidize.

- Simplified theoretical models suggests that a lesser amount of fluidization will occur in tanks without a significant liquid layer.

\section{INTRODUCTION}

This report describes the results of the Savannah River Technology Center (SRTC) program to address bubble gas release potential as requested by Concentration, Storage and Transfer Engineering. Researchers from the Waste Processing Technology Section (WPTS) and Immobilization Technology Section (ITS) contributed to the results presented.

Previously, personnel made measurements of the hydrogen concentrations in tank vapor spaces. ${ }^{2,3,4}$ These measurements demonstrated that hydrogen is released from the tank contents upon agitation. Previous laboratory work ${ }^{5,6}$ showed measurable quantities of hydrogen produced by radiolysis in tetraphenylborate slurries, sludge and saltcakes. Retention of hydrogen within High Level Waste tanks poses a potential safety concern. ${ }^{7}$ An analysis of the potential for exceeding the hydrogen flammability limit in the high level waste tanks was performed. This analysis made three primary assumptions: that sludge can contain $20 \mathrm{vol} \%$ trapped gas, that trapped gas consists of $50 \%$ hydrogen or less and that $50 \%$ of trapped gas releases during a seismic event. ${ }^{11}$ Work has been performed to identify the validity of each of these assumptions. Weber et al. ${ }^{14}$ developed a method to estimate the volume of the trapped gas in high level waste tanks. Laboratory experiments provide estimates of the fraction of hydrogen in trapped gases and the amount of trapped gas released during a seismic event. ${ }^{8,9}$ This document reports on experiments designed to illuminate the extent of gas 
released from both sludge and salt matrices. These experiments are analyzed in relation to sudden agitation that occurs during an earthquake.

Extensive work performed at Pacific Northwest National Laboratory (PNNL) estimated the quantity of gases retained in settled solids. These results indicate that for yield strengths of approximately 10 $\mathrm{Pa}$, the sludge studied could retain as much as $20 \%$ of their volume in gases. ${ }^{18}$ Those studies did not, however, indicate the quantity of gas released during agitation events and, in particular, during the design basis earthquake. This report describes experiments providing an experimental measure of gas bubble release during events similar to the design basis earthquake.

\section{DISCUSSION}

\section{Tank Considerations}

High Level Waste at the Savannah River Site generally exists in three forms, as saltcake, as sludge and as supernate. Generally speaking, all the high level waste tanks contain some quantity of supernate. However, the tanks can be divided into classes shown in Table 1.

Table 1. Classification of High Level Waste Tanks

\begin{tabular}{|c|c|}
\hline Tanks with Sludge and Supernate & Tanks with Saltcake and Supernate \\
$6 \mathrm{~F}, \mathbf{7 F}, 11 \mathrm{H}, \mathbf{1 3 H}, 22, \mathrm{H} 23 \mathrm{H}, 26 \mathrm{~F}$ & $1 \mathrm{~F}, 2 \mathrm{~F}, 3 \mathrm{~F}, 9 \mathrm{H}, 10 \mathrm{H}, 14 \mathrm{H}$ \\
$32 \mathrm{H}, \mathbf{3 5 H}, 39 \mathrm{H}, \mathbf{4 0 H}, 51 \mathrm{H}, 42 \mathrm{H}, 43 \mathrm{H}$, & $19 \mathrm{~F}, 25 \mathrm{~F}, 27 \mathrm{~F}, 28 \mathrm{~F}, 29 \mathrm{H}$ \\
& $30 \mathrm{H}, 31 \mathrm{H}, 36 \mathrm{H}, 37 \mathrm{H}, 38 \mathrm{H}$ \\
& $41 \mathrm{H}, 44 \mathrm{~F}, 45 \mathrm{~F}, 46 \mathrm{~F}$ \\
\hline Tanks with Sludge, Saltcake and Supernate & Tanks with Supernate only \\
4F, 33F 34F, 47F & $18 \mathrm{~F}, 21 \mathrm{H}, 24 \mathrm{H}$ \\
& \\
Tanks with Dried Sludge \& Saltcake & \\
$5 \mathrm{~F}, 8 \mathrm{~F}, 12 \mathrm{H}, 15 \mathrm{H}$ & \\
\hline
\end{tabular}

Hester evaluated these tanks to determine the potential impact of hydrogen release from a seismic event upon the lower flammability limit. ${ }^{11}$ This analysis assumed the following.

- No appreciable trapped gas would exist in tanks with only supernate

- (eliminating the lower right hand entry from Table 1 from consideration).

- No appreciable trapped gas released from tanks with saltcake

- (eliminating the upper right hand entry from Table 1 from consideration).

- Sludge would contain no more than $20 \%$ volume fraction trapped gas.

- The retained gas would contain $50 \%$ hydrogen.

- $50 \%$ of trapped gas would release during a seismic event.

- Supernate does not trap appreciable amounts of gas.

- Sludge layers less than 18 inches in depth do not trap gas.

This analysis indicated that 5 of the tanks in Table 1 (shown in bold) could exceed the lower flammability limit during a seismic event. ${ }^{11}$ An additional four tanks pose a concern if the operating fill limits are reached (shown in italics in Table 1).

These assumptions derived from observations of work performed at PNNL. Mahlman showed that for simple salt solutions containing more than $0.8 \mathrm{M} \mathrm{NO}_{3}^{-}$, hydrogen provides less than $50 \%$ of the 


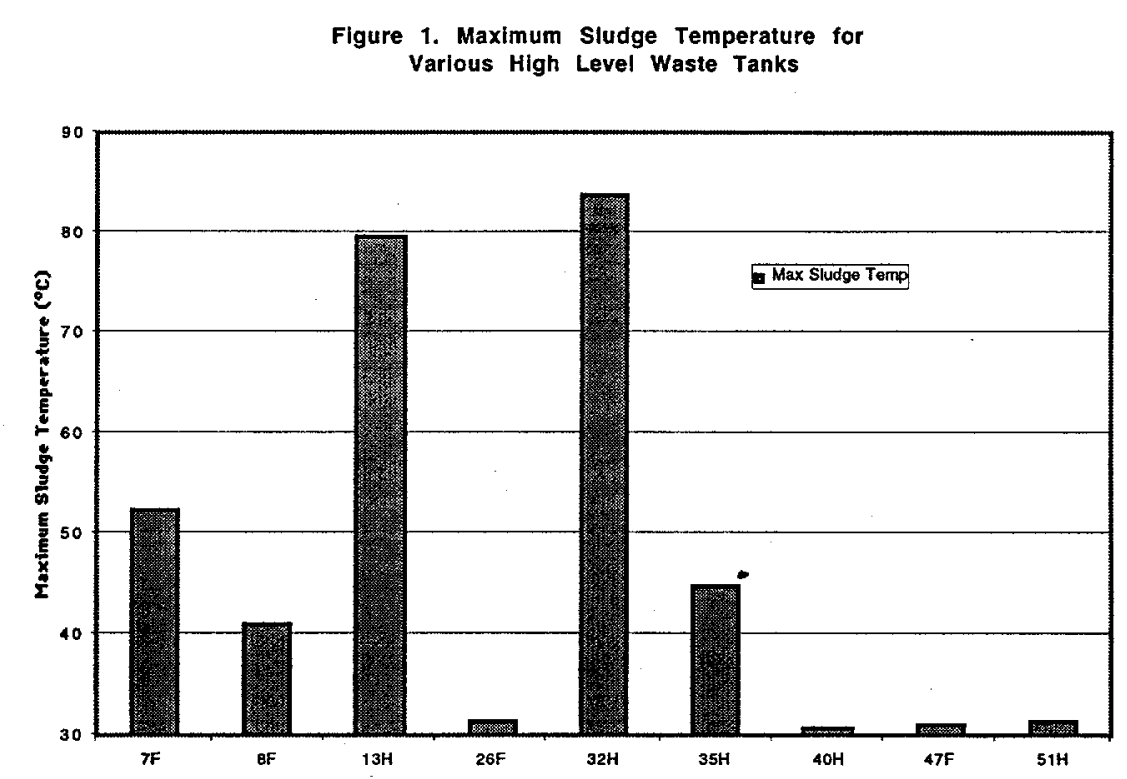

gas produced by radiolysis due to decreases in hydrogen production and increases in oxygen production. $^{12}$ As mentioned above Gauglitz showed that slurries of varying strengths generally hold less than $20 \mathrm{vol} \%$ trapped gas. Further experience at Hanford indicated that gas release events generally liberate less than $50 \%$ of the trapped gas. ${ }^{17}$ Preliminary modeling of the release from high strength materials by PNNL researchers indicated that these materials (such as saltcake) would not likely release trapped gas. ${ }^{17}$

Volume Fraction Retained More than $40 \%$ of Hanford tanks studied show less than $10 \%$ retained gas volume. ${ }^{13}$ This data suggests that many of the tanks of concern at SRS may contain significantly lower volumes of trapped gas than assumed in Hester's analysis. In determining the void fraction of trapped gas retained, PNNL researchers developed a methodology for translating level change data from High Level Waste tanks into estimates of the void fraction of trapped gas. Recently, Weber made similar measurements for one of the SRS High Level Waste tanks containing sludge (Tank $32 \mathrm{H})^{14}$. These estimates indicate that little or no trapped gas exists in Tank $32 \mathrm{H}^{14}$

This data indicates that at least one mechanism exists for the transport of hydrogen through the sludge in this tank. The most mechanism for such transport is through convective mixing of the interstitial fluid in the sludge layer. A number of the high level waste tanks of interest produce significant amounts of heat through radiolysis. If no convective heat transfer occurred in these tanks fairly high temperatures would result in these waste tanks. Figure 1 provides an estimate of the maximum temperature that could be reached in these tanks if no convection occurs. (Currently, the tanks are not being cooled and the measured sludge temperatures are near those shown on Figure 1.) Figure 1 indicates that Tanks $32 \mathrm{H}$ and $13 \mathrm{H}$ would experience very high thermal gradients. These thermal gradients would lead to convective heat transport which would also result in significant loss of hydrogen, thus providing a potential explanation for the low volume fraction trapped gas observed in Tank $32 \mathrm{H}$. Also note that Tanks $7 \mathrm{~F}, 8 \mathrm{~F}$, and $35 \mathrm{H}$ should also have significant convection, and thus may retain significantly less than $20 \%$ volume fraction trapped gas. Additional measurements of trapped gas using level change and associated vapor sampling would confirm the extent to which trapped gas is retained in these tanks.

Gas Composition 
Figure 2. Estimated Volume\% Hydrogen Produced by Radiolysis

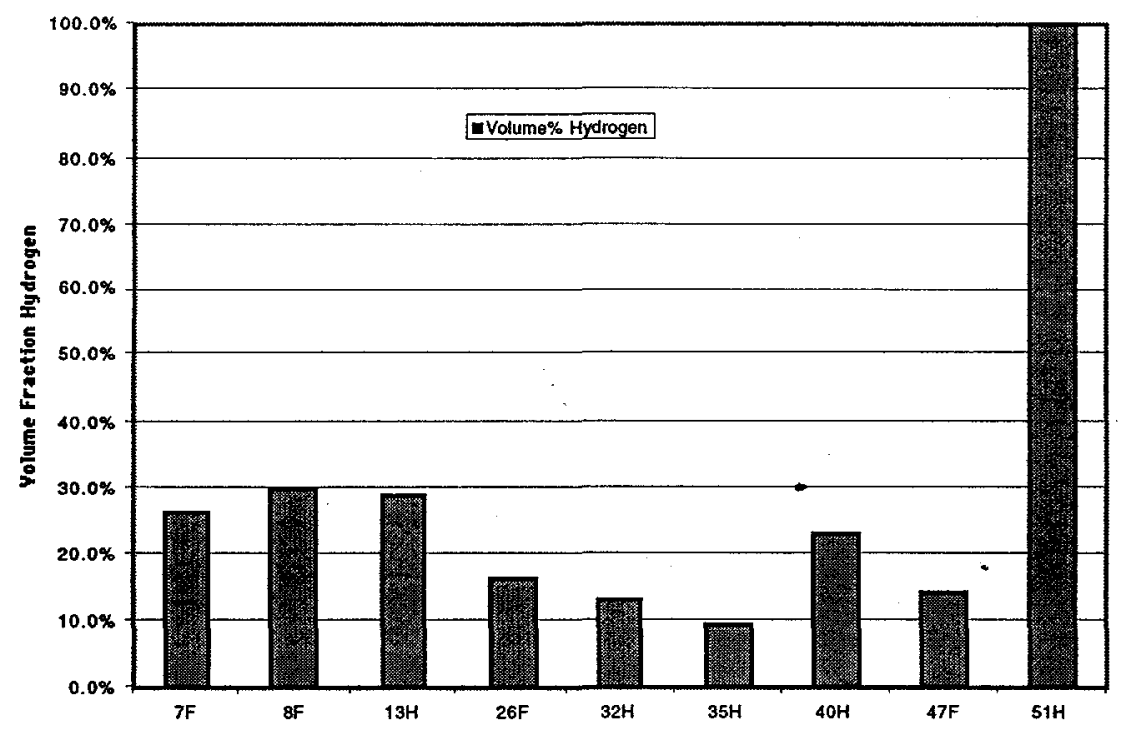

Using the nitrate ion concentrations measured in various tanks of interest, existing correlations ${ }^{12}$ provide a preliminary estimate of the concentration of trapped gas in these tanks. Figure 2 contains these estimates. Figure 2 indicates that hydrogen accounts for significantly less than $50 \%$ of the trapped gas for all cases except for Tank $51 \mathrm{H}$. If one replaces the assumption of $50 \%$ hydrogen with the values presented in Figure 2, a significantly lower hydrogen concentration in the vapor results during a seismic event for most of the tanks of interest. Based on these assumptions (and the assumption of $20 \mathrm{vol} \%$ trapped gas and $50 \%$ release), only Tanks $7 \mathrm{~F}$ and $13 \mathrm{H}$ would possibly exceed the lower flammability limit during a seismic event (see Figure 3). Furthermore, only $40 \mathrm{H}$, $47 \mathrm{~F}$ and $51 \mathrm{H}$ would exceed $50 \%$ of the LFL. To credit the lower hydrogen concentration in these tanks, future studies should confirm the hydrogen ratios in the presence of the more complex solution matrix present in the High Level Waste Tanks. In particular, the study should investigate the impact of nitrite ion and various organic compounds present in the tank farm. The presence of organic compounds such as dibutyl phosphate and oxalate will result in the oxidation of these organics and thus the net consumption of oxygen. Since oxygen is the predominant gaseous product of radiolysis of solution containing high nitrate concentrations, the reduction in oxygen production results in a higher hydrogen fraction in trapped gas. Of the tanks of interest from Table 1 (those in italics and bold), Tank $26 \mathrm{~F}$ is most likely to contain quantities of organic species that may impact the ratio of hydrogen in that tank relative to other radiolysis gases.

\section{Trapped Gas Release}

\section{Experimental Methodology}

Testing focused on the release of trapped gas from simulated waste solutions under controlled agitation. These tests used four types of simulated waste solutions and two methods for introducing trapped gas bubbles (see Table 2). The two methods of introducing gas include irradiation and by reaction of peroxide. Irradiation (to between 6 and $8 \mathrm{Mrad}$ of $\gamma$ irradiation from a Co-60 source) of these samples produced primarily $\mathrm{H}_{2}$ and $\mathrm{O}_{2}$. Peroxide decomposes in mixtures of bentonite clay and sodium hydroxide to produce $\mathrm{O}_{2}$. (Note: peroxide decomposition in simulated sludge occurs too quickly for practical use.) These tests used about $4 \mathrm{~mL}$ of $30 \mathrm{wt} \%$ hydrogen peroxide per $\mathrm{mL}$ of solution. Previous work at Pacific Northwest National Laboratory indicated that the rheological 


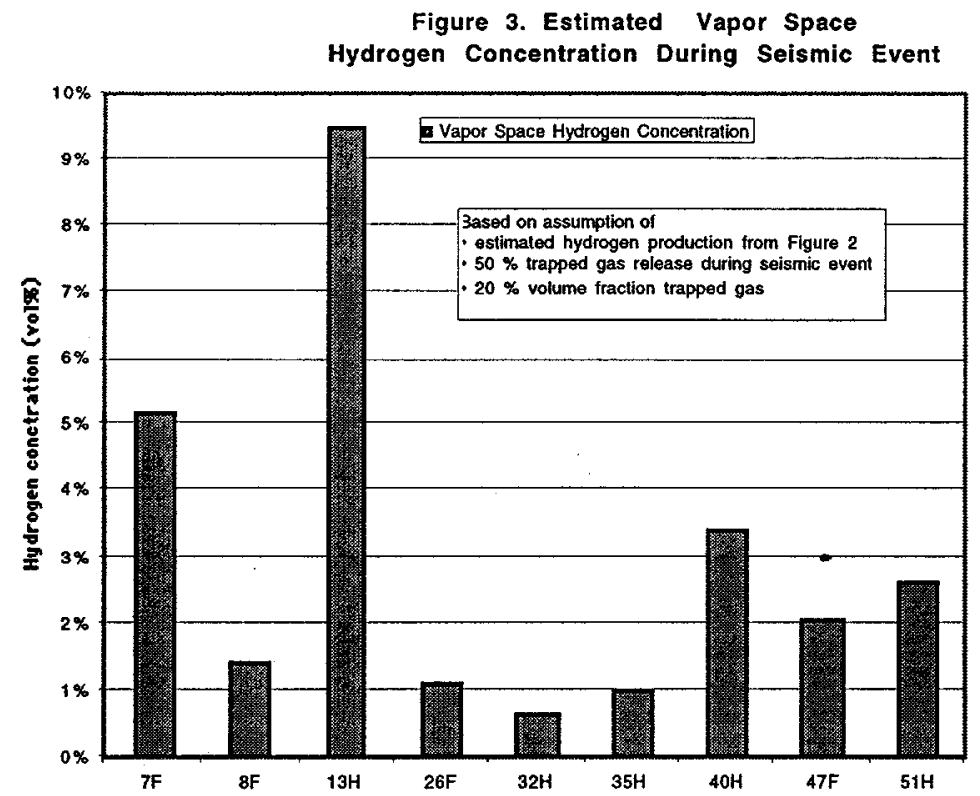

properties of 10 to $14 \mathrm{wt} \%$ bentonite clay mixtures approximate those of SRS sludge. Use of bentonite clay facilitates the development of proposed future larger-scale tests that can not utilize the Co-60 source.

Figure 4 describes the testing protocol used for those tests using irradiation for the production of trapped gases. When peroxide provided the trapped gas production, the tests used liquid level change to determine the quantity of trapped gas released. 
Figure 4. Experimental Flow Diagram for Irradiation Produced Gas.

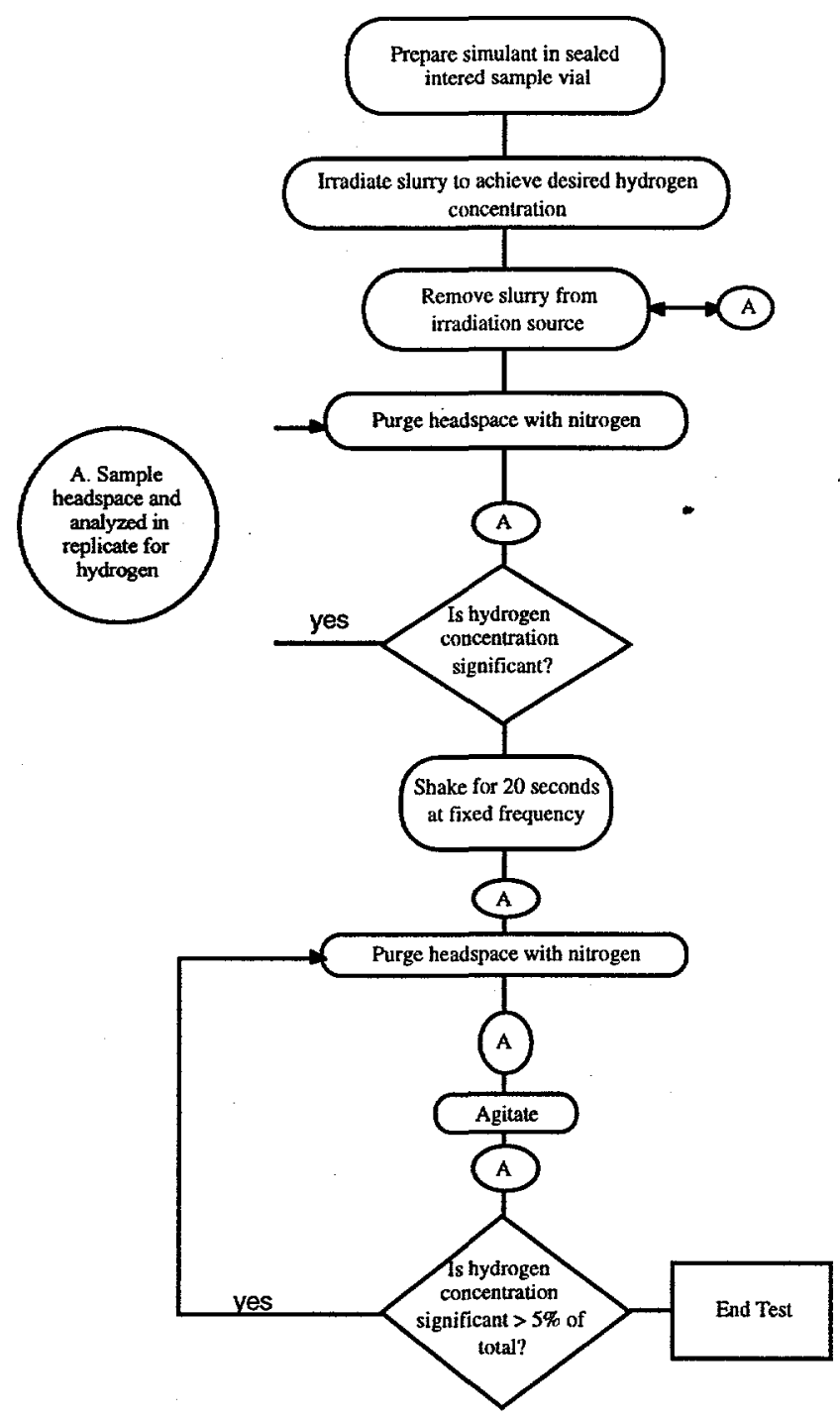

As received sludge simulant contain approximately $14 \mathrm{wt} \%$ solids. ${ }^{15}$ Concentrated sludge -- obtained by centrifuging as received sludge to achieve a $50 \mathrm{vol} \%$ reduction -- contains approximately $28 \mathrm{wt} \%$ solids. Note that the concentrated sludge would likely be more representative of settled sludge in the tank farm and the as received sludge would likely be more representative of washed sludge. However, since limited rheological data is available related to the contents of these tanks, correlations between the observed experimental results and anticipated tank results should be made carefully. It is likely that sludges in the tank farm span the behaviors observed for concentrated and as received sludge. The bentonite clay samples contained 11 to $12 \mathrm{wt} \%$ solids in water. Saltcake was prepared by evaporating a concentrated salt solution and cooling to room temperature.

Most of the tests in Table 2 used a $4 \mathrm{~cm}$ diameter vessel containing $50 \mathrm{~mL}$ of the mixture. This provided an aspect (i.e., depth-to-diameter) ratio of $\sim 1$. Two additional tests used a larger vessel ( $15 \mathrm{~cm}$ in diameter). These tests used an approximately $12 \mathrm{wt} \%$ bentonite slurry. The test vessel contained 5 and $10 \mathrm{~cm}$ of slurry for these two tests, yielding aspect ratios of 0.33 and 0.66 . These 
tests used amplitudes ranging from 1.27 to $3.81 \mathrm{~cm}$ and frequencies from 0.2 to $2.6 \mathrm{~Hz}$. These frequencies and amplitudes were selected based on results from preliminary testing that indicated for sludge simulants, trapped gas release would occur over this range of conditions. In addition, these frequencies generally span or were near the natural fluid frequencies of the systems employed. At this time, a complete understanding of the scaling of these results to tank conditions is not available. Thus, these conditions provided the maximum response to the variable of interest (including frequencies and amplitudes used).

Table 2. Number of samples prepared for each test method.

\begin{tabular}{|l|c|c|c|c|}
\cline { 2 - 5 } \multicolumn{1}{c|}{} & $\begin{array}{l}\text { As Received } \\
\text { Sludge }\end{array}$ & $\begin{array}{l}\text { Concentrated } \\
\text { Sludge }\end{array}$ & Bentonite Clay & $\begin{array}{l}\text { Prepared } \\
\text { Saltcake }\end{array}$ \\
\hline Irradiation & 10 & 2 & None & 5 \\
\hline Peroxide & none & None & 5 & None \\
\hline
\end{tabular}

Each test used a fixed stroke length displacement in one direction such that the location of the sample $(x)$ can be written as

$$
x=\frac{A}{2} \sin (f \pi t)
$$

where A represents the stroke length $(\mathrm{cm}), \mathrm{f}$ corresponds to the frequency $(\mathrm{Hz})$, and $\mathrm{t}$ is time $(\mathrm{s})$. The velocity $(v)$ is:

$$
v=\frac{d x}{d t}=2 f \pi \frac{A}{2} \cos (2 f \pi t)
$$

and the acceleration $(a)$ is:

$$
a=\frac{d v}{d t}=\frac{d^{2} x}{d t^{2}}=-4(f \pi)^{2} \frac{A}{2} \sin (2 f \pi t)
$$

Thus, as the frequency increases, the acceleration - and thus the force acting on the sample-increased dramatically.

\section{Experimental Results}

\section{$\underline{\text { Saltcake }}$}

Table 2 states that 5 tests investigated the impact of agitation on the release of trapped gas from saltcake. Initially, these samples were agitated in a controlled fashion. Analyses of these samples did not indicate any release of hydrogen. Additional strong agitation of this sample also provided less than detectable concentrations of hydrogen release. These results support the assumption that limited hydrogen will release from saltcake during a seismic event. The presence of layers of fluid sandwiched between salt cake layers was not addressed in this analysis.

\section{Sludge}

Tests performed using the sludge/hydrogen system indicated that the changes of the agitation frequencies affected each sample identically (see Figure 5). The system released a greater percentage of the trapped gas as the agitation frequency increased. Also note that as the agitation frequency 
increased, the amount of material in motion (i.e., sloshing) in the vessel increased. These tests used sludge simulants with relatively low yield strengths.

Additional tests using concentrated sludge provided significantly different results. The samples did not release measurable quantities of trapped gas when agitated, even at $4 \mathrm{~Hz}$. The sludge sample did release measurable trapped gas when vigorously shaken by hand (see Figure 5). In Figure 5, the data point shown at $4.5 \mathrm{~Hz}$ represents shaken by hand, but not specifically at $4.5 \mathrm{~Hz}$. These results suggest that more concentrated sludge samples (such as would be present near the bottom of a high level waste tank) would be less susceptible to release, while more dilute sludge (as would be present near the top of the sludge layer) would be more susceptible. It is likely that sludges in the tank farm span the behaviors observed for concentrated and as received sludge.

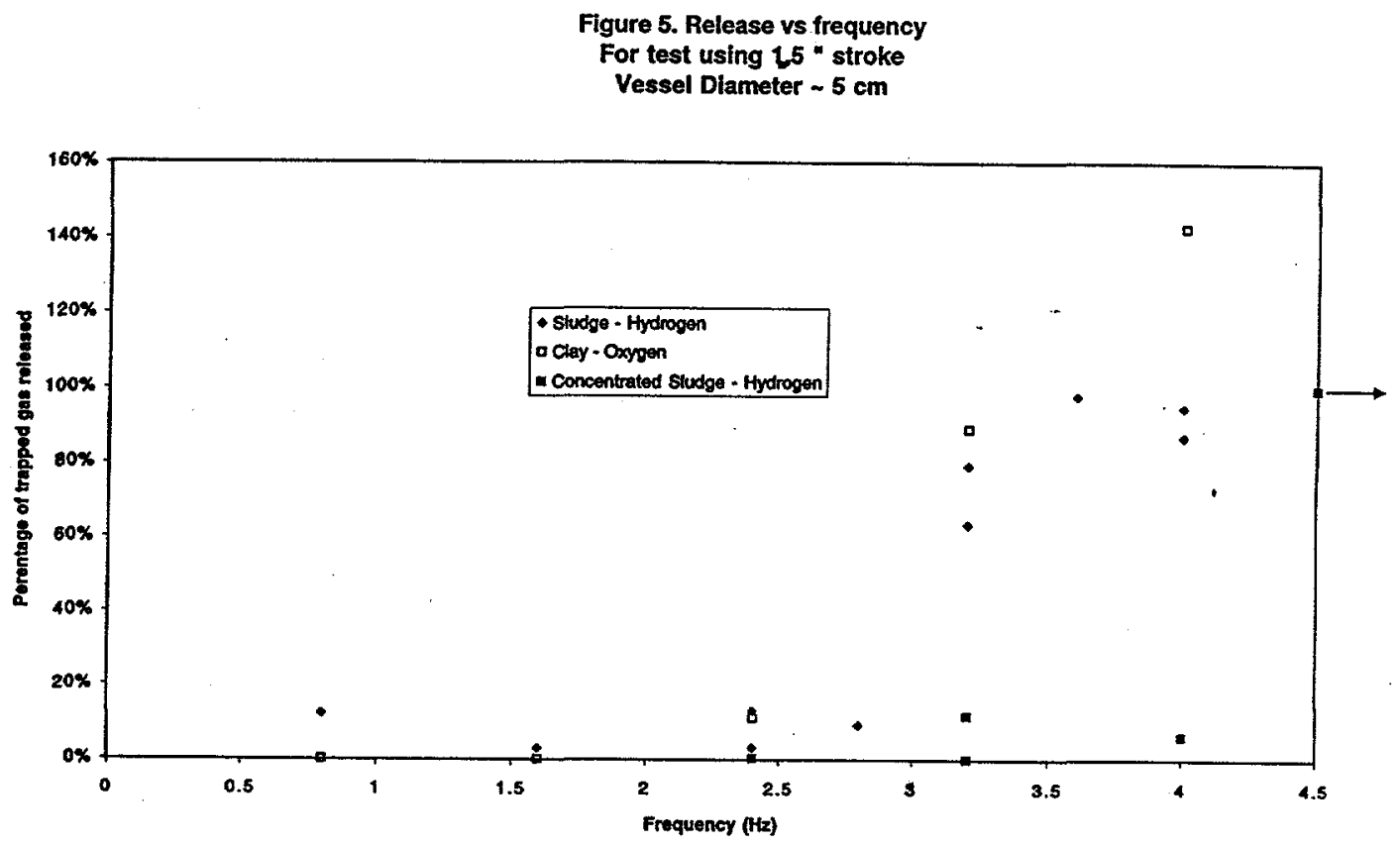

Clay

Figure 5 indicates relatively sharp dependence of trapped gas release on the amount of energy applied. Also, the amount released depends on strength of the retaining media. Note that for the clay samples, the amount of trapped gas released was determined by measuring the level before introduction of trapped gas, after introduction of trapped gas and after agitation.

Comparison of the unconcentrated and concentrated sludge samples readily shows the difference. At identical accelerations, the thicker - by $2 \mathrm{X}$ solids content - material produced completely different amounts of released trapped gas. The data suggest that fluidization of the material (and thus release) depends on a relationship between the force applied to the material and the strength of the material. In one case, the level after agitation was lower than prior to introduction of trapped gas. This suggests that a small amount of trapped gas existed in the system prior to testing and that this gas was released during agitation.

The experiments also studied release from larger (i.e., $15 \mathrm{~cm}$ diameter) vessels. In contrast to the work with smaller vessels, these tests examined a scan of both amplitude and frequency. At low frequency and amplitude, the material in the vessel behaved as a solid mass (see Figure 6A). At 
slightly increased frequency and amplitude, fluidization of the material occurred near the edges of the vessel (see Figure 6B). As energy input increased, this fluidization propagated through the material until, with enough energy supplied, the entire material fluidized (see Figure 6C and 6D). The tests proved that only the sloshing regions released the trapped gas. Other literature refers to the sloshing material as convective layers. ${ }^{16}$ The tests also examined effect of the agitation frequency on the depth of the convective layer. As the frequency increased, the convective layer expanded in depth. This expansion in the convective layer directly corresponded to an increase in the amount of gas released.

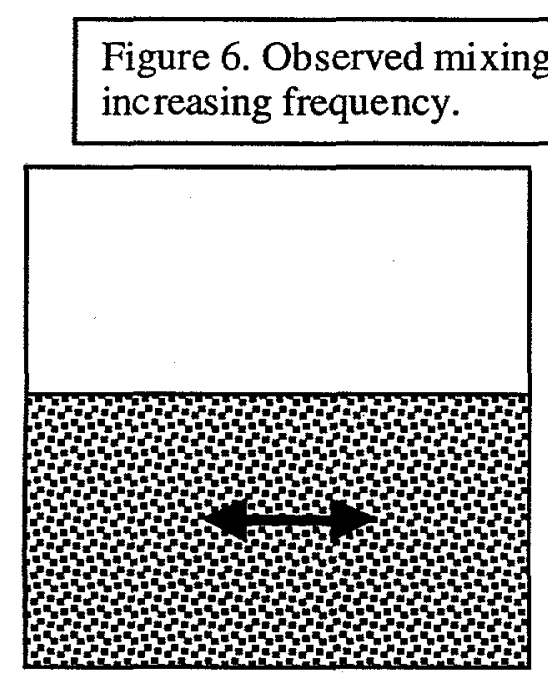

Figure 6A

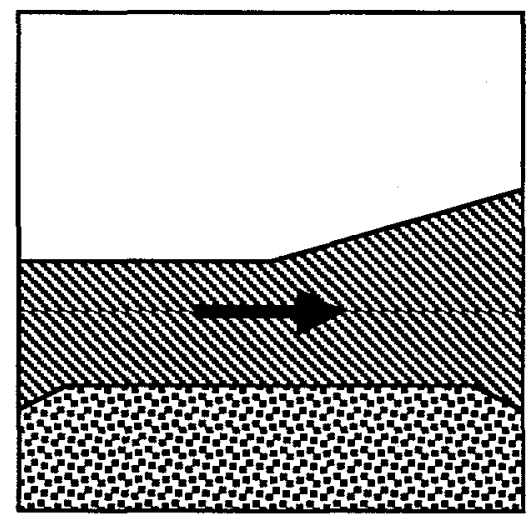

Figure 6C

(1) Unmixed zone with trapped gas

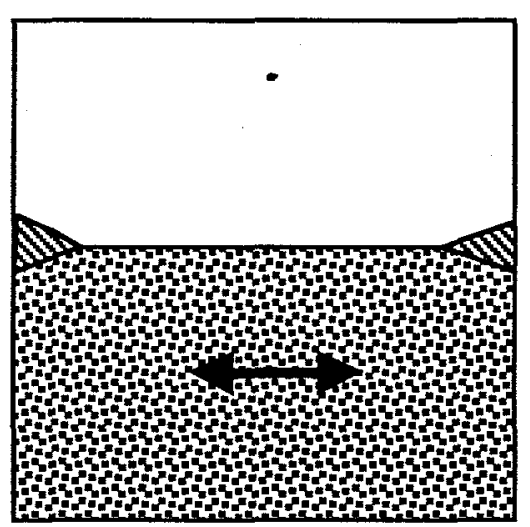

Figure 6B

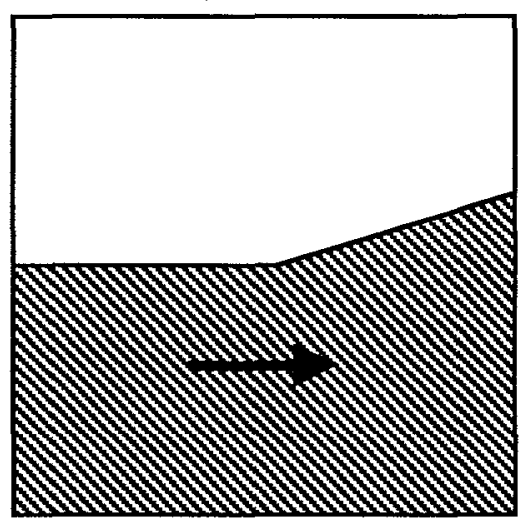

Figure 6D

Mixed zone without trapped gas

\section{Computer Simulations}

Researchers at PNNL developed a highly refined analytical model of the behavior of this material. ${ }^{17}$ However, it is insightful to first consider a highly simplified interpretation of the behavior of this material. Consider the material as a solid body moving horizontally in one direction at a given acceleration. Neglecting any elasticity of the material, the force acting on the material is simply the product of the mass and acceleration. If one considers a single element of the material, (with cross 
section of $1 \mathrm{~cm}^{2}$ ) the force acting on the material is simply the product of the acceleration and the column length (see Figure 6A). Thus, it is possible to provide a very crude estimate of the maximum force (and pressure) generated by the acceleration of the material. If this pressure exceeds the yield strength of the material, one may anticipate yielding (and thus localized fluidization) of the material. Figure 7 provides this rough estimate of the lateral accelerations overcoming the yield strength of these materials.rs complicates this analysis and has not been addressed herein. These results suggest that more concentrated sludge samples (such as would be present near the bottom of the tank) would be less susceptible to fluidization.

Modeling results from Reid and Deibler ${ }^{17}$ and Wassgren (see Appendix A) estimate that fluidization of the material will occur only near the surface of the tank. While neither of these models provide a rigorous description of the material behavior after the translation to fluid material, they do suggest that when no overlaying liquid exists, material of moderate strength will likely fluidize only near the surface of the tank during a seismic event. Verification that this behavior for tanks containing little or no liquid layer requires extensive data on the physical properties of these materials including a measure of the shear/strain relationship. As noted above, fluidization of weak material will occur. The degree of fluidization that occurs will vary in inverse proportion to the strength of the material. Thus, use of either of these models requires that tanks contain both a small amount of free liquid (not generally true of SRS tanks containing sludge) and thorough understanding of the material properties of the sludge (also generally lacking for SRS High Level Waste).

When the work of Reid and Deibler and of Wassgen analyzed the system containing a significant free liquid layer, they predicted fluidization of the majority of the sludge in the tank. While laboratory testing did not study this phenomenon, such behavior is expected to occur to a limited extent in the High Level Waste Tanks. Due to the ability to store energy in the free liquid layer, more energy can be transfered to the sludge when a free liquid layer exists. However, again, neither of these two models adequately describes the transition from solid to fluid behavior. If a more complete model proves desirable for program needs, additional refinement would focus on more accurately describe this transition. However, the development of such models likely represents a fairly extensive effort.

\section{CONCLUSIONS}

Hester's analysis of High Level Waste tanks identified nine tanks as most vulnerable to release of hydrogen during a seismic event in sufficient quantities to pose a flammability hazard. Laboratory testing of saltcake confirms the assumption that tanks containing only saltcake will not release significant quantities of trapped gas even when exposed to relatively large accelerations. Testing with simulated sludge with rheological properties typical of High Level Waste supports the contention that the solids retain no more than $20 \mathrm{vol} \%$ of trapped gases. ${ }^{10}$ In current analyses, sloshing of supernate over sludge results in fluidization and the release of trapped gas. Less fluidization occurs in tanks without a significant liquid layer. Calculations based on existing radiolysis studies suggests that the assumption of $50 \%$ hydrogen in the trapped gas appears overly conservative for all but one of the nine tanks, although additional testing in progress more rigorously evaluates this assumption.

Parallel work By Weber et al. and Bollinger and Hester suggest low volumes of trapped gas in Tank $32 \mathrm{H}$. Calculations within show that such low retention may result from good transport of the gas due to thermally induced convection. Additional vapor sampling, and use of installed humidity and pressure monitoring equipment as deployed for Tank $32 \mathrm{H}$ would further support this contention. Of the nine identified tanks, Tanks $7 \mathrm{~F}$ and $13 \mathrm{H}$ most likely benefit from this mixing. Efforts should 
focus on determining the quantity of retained gas. Without credit for lower gas retention, these two tanks might exceed the flammability limit of hydrogen during a seismic event.

\section{REFERENCES}

'B.E. Lewis, "Technical Task Request: Hydrogen Release from Sludge and Salt Cake", HLE-TTR-98046, April 21, 1998.

${ }^{2}$ R. A. Peterson, R. F. Swingle, "Hydrogen Retention and Release Summary From Tank 48H from September 1995 to October 1996 (U), WSRC-TR-97-0043, February 10, 1997.

${ }^{3}$ W. C. Walker to E. Lee "Evolution of Hydrogen form Tank 51 During Initial Run-In of Three Slurry Pumps", October 15, 1993

${ }^{4}$ D.T. Hobbs, P.W. Norris, S.A. Pucko, N.E. Bibler, D.D. Walker and P.D. d'Entremont, "Hydrogen Generation Rates in Savannah River Site High-Level Nuclear Waste", Proceedings of Waste Management 1992, Vol. 1, March, 1992.

${ }^{5}$ C.L. Crawford and D.D. Walker, "Hydrogen Generation by Radiolysis of Tetraphenylborate Solutions and Slurries (U)", WSRC-TR-96-0109, June 19, 1996.

${ }^{6}$ D. D. Walker, "Potential Gas Liberation During Tank 41H Salt Dissolution", WSRC-TR-95-0032, January 31, 1995

${ }^{7}$ S.M. Hall, "Potential for Release of Hydrogen as a Result of Waste Tank Agitation", NI-HLW-96-014,R2, May $13,1997$.

${ }^{8}$ R. A. Peterson, "Task Technical Plan for Hydrogen Release from Sludge and Salt Cake" April 21, 1998, WSRCRP-98-00154.

${ }^{9}$ R. A. Peterson and C.L. Crawford, "Task Technical Plan for Hydrogen Production from Radiolysis of Sludge Systems" September 15, 1998, WSRC-RP-98-01073.

${ }_{10}^{10}$ P.A. Gauglitz, S.D. Rassat, P.R. Bredt, J.H. Konynenbelt, S.M. Tingey, D.P. Mendoza, "Mechanisms of Gas Bubble Retention and Release: Results for Hanford Waste Tanks 241-S-102 and 241-SY-103 and Single-Shell Tank Simulants", PNNL-11298, September 1996.

${ }^{11}$ F/H Tank Farm Emergency Response and Waste Tank Status Data, N-ESR-G-00001, Revision 26, September 1998.

${ }^{12}$ H.A. Mahlman, "The OH Yield in the $\mathrm{Co}^{60} \gamma$ Radiolysis of HNO3", Journal of Chemical Physics, 35, 3, September 1961.

${ }_{13}$ C.W. Stewart, M.E. Brewster, P.A. Gauglitz, L.A. Mahoney, P.A. Meyer, K.P. Recknagle, H.C. Reid, "Gas Retention and Release Behavior in Hanford Single-Shell Waste Tanks", PNNL-11391, December 1996.

${ }_{14}^{14}$ A. Webber, Tank 32 Measurements, Personal Communication.

${ }_{10}^{15}$ R.E.Eibling. simulant prep.

${ }^{16}$ H.E. Flanders, "ITP Waste Tanks Seismic Sloshing Horsepower, PEC-EAT-97-0012, March 25, 1997.

${ }^{17}$ H.C. Reid and J.E. Deibler, "Earthquake-Induced Response and Potential for Gas Mobilization in Hanford Waste Tanks, PNNL-11668, September 1997. 
WSRC-TR-98-341

Revision 0

Page 13 of 13

September 24, 1998

Approvals

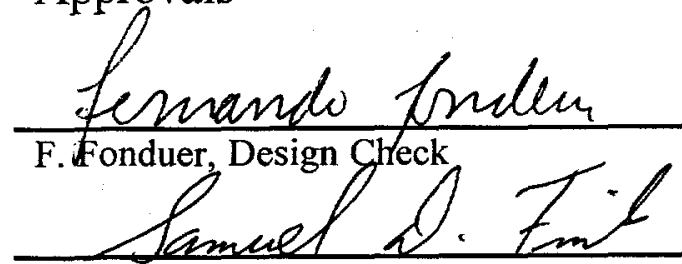

$9-24-58$

S. D. Fink, Manager, Manager WPTS-LWP

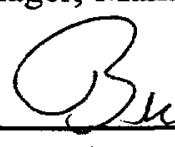

B. L. Lewis, Manager Concentration, Storage and Transfer Engineering
Date $9-24-98$

Date

$9-24-98$

Date 